\title{
Las raíces isabelinas del teatro por horas y su primer repertorio: en torno a los orígenes del género chico*
}

\author{
The Isabelline Roots of teatro por horas \\ and its Early Repertoire, in Relation to the \\ Origins of the género chico
}

Los principales historiadores del denominado "género chico" han insistido en señalar el estrecho vínculo entre la Revolución de 1868 y el nacimiento del teatro por horas en Madrid. Para ellos, la idea de explotar las funciones teatrales por sesiones surgió como respuesta a una pulsión de ocio exigida por el nuevo orden social democrático. Sin embargo, nuestra perspectiva de la cronología y naturaleza de los acontecimientos es diametralmente opuesta, ya que consideramos que el teatro por horas nace como consecuencia de la realidad sociocultural del último periodo de reinado de Isabel II. En este artículo pretendemos profundizar en las raíces isabelinas del teatro por horas ya que, al menos desde 1866, podemos localizar espacios teatrales donde se ofrecían hasta cuatro funciones diarias. El asunto del repertorio de estas salas, el primer género chico, así como su recepción crítica e historiográfica será el otro eje sobre el que centraremos nuestro texto.

Palabras clave: teatro, teatro por horas, género chico, zarzuela, café-teatro, café-concierto, café-cantante, historiografía.

The principal historians of the so-called género chico have insistently pointed out the close link between the 1868 Revolution and the birth of teatro por horas in Madrid. For them, the idea of organising theatrical performances by session arose in response to a leisure drive demanded by the new, democratic social order. However, our perspective on the chronology and nature of these events is diametrically opposed, since we consider that teatro por horas emerged as a consequence of the sociocultural reality of the last period of Isabel II's reign. In this article we purpose to delve into the Isabelline roots of teatro por horas, since-at least from 1866-we can identify theatrical spaces where up to four daily functions were offered. The subject of the repertory of these auditoria - the first género chico- as well as its critical and historiographic reception, will be the other axis on which our text is centred.

Keywords: theatre, teatro por horas, género chico, zarzuela, café-teatro, café-concierto, café-cantante, historiography.

Si se realiza un repaso de algunas de las referencias historiográficas sobre el género chico, se puede observar cierta complicidad entre autores clásicos y contemporáneos por destacar la fecha simbólica de 1868 como el

*Una versión preliminar de este artículo se presentó en el marco de las II Jornadas de estudio sobre la vida musical en la España isabelina "Definiciones y fronteras", organizadas por la Sociedad para el Estudio de la Música Isabelina en Madrid, los días 7 y 8 de marzo de 2014. 
momento de su nacimiento. Son pocos los autores que se han resistido a relacionar la trascendencia de los acontecimientos revolucionarios de aquel año y del Sexenio Democrático con el novedoso sistema de explotación del teatro por horas. Era casi inevitable redundar en una sincronicidad tan vistosa, historiográficamente hablando, si convenimos con Serge Salaün en que el citado teatro por horas implicaba "una auténtica 'democratización' de los espectáculos". Sin embargo, en las siguientes líneas pretendemos ofrecer una breve relectura de los acontecimientos profundizando en las raíces isabelinas del teatro por horas. Contamos con testimonios suficientes como para proponer un enfoque menos sexenista de la cuestión; tal vez un nuevo paradigma que nos obligue a preguntarnos sobre el propio concepto de género chico.

\section{Construcción y deconstrucción de un modelo historiográfico}

La inercia por vincular el nacimiento del teatro por horas con la Revolución Gloriosa y sus consecuencias es patente en los principales investigadores del tema desde el ámbito de la libretología o los estudios teatrales. En los trabajos monográficos más divulgados sobre este asunto ${ }^{2}$ se propone generalmente, como fecha simbólica de consagración del teatro por horas, la de 1870, con la apertura en Madrid de varias salas con dicho funcionamiento, la libertad de teatros decretada un año antes, la llegada a la capital de una nueva generación de autores o la revitalización del sainete como género. Se ha buscado un origen al teatro por horas que funcionase bien en paralelo a la historia política y que confirmase el modelo historiográfico organicista propuesto, con fechas tan redondas, por José Deleito Piñuela: "En líneas generales, la historia del género chico puede reducirse a tres etapas, correspondientes a otras tantas décadas: de 1880 a 1890, formación; de 1890 a 1900, plenitud; de 1900 a 1910, decadencia y muerte"3. Deleito considera la década anterior al estreno de La canción de la Lola (1880), la de los años setenta, como la de "infancia del género", presuponiendo que apenas hay

\footnotetext{
1 Serge Salaün: "El público de los espectáculos (mal llamados) menores (1875-1936)", Les espectacles en Espagne (1875-1936), París, Presse Sorbonne Nouvelle, 2011, p. 177.

2 María Pilar Espín Templado: El teatro por horas en Madrid (1870-1910), Madrid, Instituto de Estudios Madrileños-Fundación Jacinto e Inocencio Guerrero, 1995; Fernando Doménech Rico (ed.): La zarzuela chica madrileña [...], Madrid, Editorial Castalia-Consejería de Educación y Cultura de la Comunidad de Madrid, 1998; Carmen del Moral Ruiz: El género chico. Ocio y teatro en Madrid (18801910), Madrid, Alianza, 2004; Alberto Romero Ferrer (ed.): Antología del Género Chico, Madrid, Cátedra, 2005; Margot Versteeg: De fusiladores y morcilleros. El discurso cómico del género chico (1870-1910), Ámsterdam, Atlanta, Rodopi, 2000.

${ }^{3}$ José Deleito y Piñuela: Origen y apogeo del género chico, Madrid, Revista de Occidente, 1949, p. 177. Este modelo, sin alteración ninguna, ha sido transmitido por Espín Templado en su referencia ya citada de 1995, pp. 45-56.

${ }^{4}$ J. Deleito y Piñuela: Origen y apogeo..., p. 1
} 
zarzuelas interpretadas dentro de este tipo de salas de "a real la pieza" durante esos primeros años ${ }^{5}$. En último término, Deleito y Piñuela se basaba en los planteamientos del primer cronista del género chico, Marciano Zurita, que en 1920, además de insistir en la fecha referencial de 1868, canonizaba ya a La canción de la Lola como "la primera zarzuela del 'género chico' que merece ese honroso calificativo".

Este modelo interpretativo ha sido el que ha cundido en la musicología española contemporánea, una musicología que, hasta hace apenas treinta años, no ha empezado a considerar con seriedad el estudio de la zarzuela y que, con la excepción de la obra de Francisco Asenjo Barbieri, Ruperto Chapí, Tomás Bretón, Tomás Barrera y José Serrano ${ }^{7}$, desconoce desde el punto de vista analítico ${ }^{8}$ el grueso del repertorio del denominado género chico ${ }^{9}$. Asumido el citado modelo interpretativo, no es de extrañar que prácticamente ningún musicólogo se haya interesado por el estudio de esos diez primeros años de penumbra historiográfica (ca. 1870-1880) ${ }^{10}$. Así, Emilio Casares propone en el Diccionario de la zarzuela ${ }^{11}$ el año de 1880 como el del comienzo del género chico propiamente musical con el estreno de La canción de la Lola. Este hecho, junto a su visión del repertorio bufo en negativo, como "la primera crisis de la zarzuela"12 (su deuda con Antonio Peña y Goñi en este punto es indudable ${ }^{13}$ ), ha podido influir en el desinterés por la zarzuela chica y bufa de estos años.

${ }^{5}$ Ibid., p. 13.

${ }^{6}$ Marciano Zurita: Historia del género chico, Madrid, Prensa Popular, 1920, p. 28.

${ }^{7}$ Emilio Casares Rodicio: Francisco Asenjo Barbieri. 1. El hombre y el creador, Madrid, ICCMU, 1994; Luis G. Iberni: Ruperto Chapí, Madrid, ICCMU, 1995; Víctor Sánchez: Tomás Bretón. Un músico de la Restauración, Madrid, ICCMU, 2002; Octavio J. Peidró: Tomás Barrera. La zarzuela de la desmemoria, Madrid, Alpuerto, 2016; Ramón Ahulló Hermano: José Serrano (1873-1941): del músico popular al compositor desconocido, Valencia, Institución Alfons el Magnànim, 2017.

${ }^{8}$ Elena Torres: "Zarzuela y musicología. Historia de un debate en permanente revisión", Horizontes de la zarzuela, Alberto González Lapuente y Alberto Honrado Pinilla (eds.), Madrid, Fundación Jacinto e Inocencio Guerrero, 2014, pp. 56-57.

${ }^{9}$ Debemos dejar constancia de la reciente defensa de dos tesis doctorales sobre compositores de género chico tan importantes como Gerónimo Giménez (Amalia Moreno Ríos: Gerónimo Giménez. Catalogación y estudio de su producción musical, Universidad de Sevilla, 2013) y Manuel Fernández Caballero (Nuria Blanco Álvarez: El compositor Manuel Fernández Caballero (1835-1906), Universidad de Oviedo, 2015). En curso hay otra tesis doctoral sobre Manuel Nieto (Andrea García Torres: La labor compositiva de Manuel Nieto [1844-1915]. Su contribución lírica al repertorio del género chico, Universidad de Oviedo).

${ }^{10}$ Honrosas excepciones que cumplen la norma son las monografías escritas por María Encina Cortizo e Inmaculada Matía sobre Emilio Arrieta y José Inzenga respectivamente; dos compositores en plena actividad compositiva durante los años que estudiamos. María Encina Cortizo: Emilio Arrieta. De la ópera a la zarzuela, Madrid, ICCMU, 1998; Inmaculada Matía Polo: José Inzenga. La diversidad de acción de un músico español en el siglo XIX (1828-1891), Madrid, Sociedad Española de Musicología, 2010.

${ }^{11}$ Emilio Casares Rodicio: "Zarzuela", Diccionario de la zarzuela. España e Hispanoamérica, E. Casares Rodicio (dir.), vol. 2, Madrid, ICCMU, 2003, p. 1022.

12 Ibid.

${ }^{13}$ Antonio Peña y Goñi: La ópera española y la música dramática en España en el siglo XIX. Apuntes históricos, Madrid, Imp. y Est. de "El Liberal", 1881, p. 586 y ss. 
El modelo historiográfico que la musicología española ha utilizado para comprender la zarzuela se cimienta sobre cierto nacionalismo y la consideración de lo breve como menor y lo bufo como frívolo, por tanto ajeno a la historia de los grandes títulos ${ }^{14}$. Esta historiografia en lugar de fundamentarse en el análisis de las obras ha estado más atenta al "peso" de las mismas y a su número de actos: género grande versus género chico "y todo lo demás" 15 . En este sentido, no fue el estudio sistemático, hasta cierto punto analítico y rigurosamente positivista de Emilio Cotarelo y Mori ${ }^{16}$ el que cundió entre los primeros estudiosos académicos de la zarzuela, sino el más literario y sentimental del citado Deleito y Piñuela, Matilde Muñoz ${ }^{17}$ o Víctor Ruiz Albéniz ${ }^{18}$. En consecuencia, el género chico anterior a 1880 ha sido ignorado y el posterior a 1910 se ha dado por decadente ${ }^{19}$.

Afortunadamente, hoy podemos significar a varios autores que en los últimos años, desde enfoques muy distintos, están ocupándose de reestudiar la zarzuela proponiendo novedosos puntos de vista para el tema que aquí tratamos. Junto a un profesor de referencia ineludible como Serge Salaün ${ }^{20}$, desde el ámbito de los estudios literarios y culturales, podríamos citar, por ejemplo, a Agnes Model ${ }^{21}$ y sus innovadores trabajos sobre el sainete lírico, a Clinton D. Young ${ }^{22}$ con su interesante análisis desde la óptica del nacionalismo del, por él denominado, teatro musical popular español, o a MargotVersteeg ${ }^{23}$ y a Lucy D. Harney ${ }^{24}$, que han profundizado en el estudio de

\footnotetext{
${ }^{14}$ Enrique Mejías García: "Cuestión de géneros: la zarzuela española frente al desafío historiográfico", Dimensiones y desafíos de la zarzuela, Tobias Brandenberger (ed.), Münster, LIT Verlag, 2014, pp. 19-41.

${ }^{15}$ Ha reflexionado sobre esta llamativa ausencia del análisis musical en los estudios sobre zarzuela Elena Torres Clemente: "Zarzuela y musicología...", pp. 45-59.

${ }^{16}$ Emilio Cotarelo y Mori: Historia de la zarzuela o sea el drama lírico en España, desde su origen a fines del siglo XIX, Madrid, Tipografía de Archivos, 1934.

${ }^{17}$ Matilde Muñoz: Historia del teatro en España. III, La zarzuela y el género chico, puesta al día con un apéndice de Álvaro Retana, 2. ${ }^{a}$ ed., Madrid, Tesoro, 1965 (1. ${ }^{a}$ ed. 1948).

18 Víctor Ruiz Albéniz ("Chispero"): Teatro Apolo. Historial, anecdotario y estampas madrileñas de su tiempo (1873-1929), Madrid, Prensa Castellana, 1953.

${ }_{19}$ Para lo que tiene que ver con el género chico de los primeros años del siglo XX véase la síntesis ofrecida en E. Mejías García: "Manuel de Falla en el contexto del género chico madrileño: nuevas respuestas a un viejo problema", Quodlibet, vol. 55, n. ${ }^{\circ} 1$, enero-abril 2014, pp. 7-39.

20 S. Salaün: Les espectacles en Espagne...

${ }^{21}$ Agnes Model: "¿Una copia exacta de la vida? Las estructuras sociales y su función en el sainete lírico de la Restauración”, De la zarzuela al cine. Los medios de comunicación populares y su traducción de la voz marginal, Max Doppelbauer, Kathrin Sartingen (eds.), München, Martin Meidenbauer, 2010; id: "La música en el sainete lírico: una propuesta metodológica basada en el análisis de las funciones musicales de la banda sonora", Revista de Musicología, vol. 32, n. ${ }^{\circ} 2$, 2009, pp. 603-621.

22 Clinton D. Young: Music Theatre and Popular Nationalism in Spain, 1880-1930, Baton Rouge, Lousiana State University Press, 2016; id.: "Theatrical reform and the emergence of mass culture in Spain", Sport in Society, vol. 11, 2008, pp. 630-642.

${ }^{23} \mathrm{M}$. Versteeg: op. cit.

${ }^{24}$ Lucy D. Harney: "Controlling resistance, resisting control: the género chico and the dynamics of mass entertainment in late nineteenth-century Spain", Arizona Journal of Hispanic Cultural Studies, n. ${ }^{\circ} 10$, 2006, pp. 151-168.
} 
repertorios alternativos al canon, autores "festivos" (por no decir "malditos"), recepciones diversas, etc. También se ha sumado a esta vía de estudios el profesor Tobias Brandenberger ${ }^{25}$ quien, además, ha editado sendos volúmenes fruto de dos coloquios sobre zarzuela en la Universidad de Gotinga (Alemania) ${ }^{26}$. Desde la musicología española tampoco han faltado voces alternativas, como la de Ignacio Jassa Haro, que reivindica el género chico musical de los años setenta ${ }^{27}$ o la de José Luis Temes, que, además de proponer una personal periodización por generaciones para la historia de la zarzuela, plantea la zarzuela bufa y el teatro por horas en positivo, como "alternativas" de trabajo o "diversificaciones" para los autores de la primera generación de zarzuelistas ${ }^{28}$.

\section{Del teatro al café: los primeros cafés-teatros madrileños}

A mediados del siglo XIX la palabra zarzuela era defendida por compositores como Barbieri, que veían en esta forma de teatro lírico "la misma cosa que las óperas cómicas francesas sin más diferencia que el idioma y el vestido musical, cortado a la española con que se las engalana" ${ }^{29}$. Como explica Demetrio Castro para lo que tiene que ver con los autores de la generación del compositor de Los diamantes de la corona:

En cierto modo, además de promotores de una empresa teatral, aquel conjunto de artistas se sentía responsable de una empresa cultural más difusa pero no menos importante, el establecimiento de un género lírico específicamente español, para públicos españoles e inspirados en recursos musicales y dramáticos propios. En cierto modo, una obra de enaltecimiento nacional ${ }^{30}$.

Sin embargo, en torno a 1860 podemos considerar que dicha empresa cultural, aquella aspiración operística del género promulgada por Barbieri,

\footnotetext{
25 Tobias Brandenberger: "Semos tercos, semos rudos'. Lectura imagológica de dos zarzuelas chicas", Lengua, Llengua, Llingua, Lingua, Langue. Encuentros filológicos (ibero)americanos, Yvette Bürki, Manuela Cimeli y Rosa Sánchez (eds.), Múnich, Peniope, 2012, pp. 74-91.

26 T. Brandenberger (ed.): Dimensiones y desafíos de la zarzuela, Münster, Lit Verlag, 2014; T. Brandenberger, Antje Dreyer (eds.): La zarzuela y sus caminos. Del siglo XVII a la actualidad, Münster, Lit Verlag, 2016.

${ }^{27}$ Ignacio Jassa Haro: "La salsa de Aniceta. Una propuesta pedagógica", Los oficios de la zarzuela, A. González Lapuente y A. Honrado Pinilla (eds.), Madrid, Fundación Jacinto e Inocencio Guerrero, 2015, pp. 35-36.

28 José Luis Temes: El siglo de la zarzuela. 1850-1950, Madrid, Siruela, 2014, pp. 44-53.

29 Francisco A[senjo] Barbieri: "La zarzuela. Consideraciones sobre este género de espectáculos. Conclusión”, La Zarzuela, 11-2-1856, p. 1. En todas las referencias que ofrecemos de prensa histórica normalizamos la ortografía y la puntuación de acuerdo a las convenciones actuales y corregimos erratas tipográficas.

30 Demetrio Castro: "Tipos y aires. Imágenes de lo español en la zarzuela de mediados del siglo XIX", Ayer, n. ${ }^{\circ}$ 72, 2008 (dosier "Espectáculo y sociedad en la España contemporánea"), p. 60.
} 
podía darse prácticamente por naufragada ${ }^{31}$. Hemos profundizado en un artículo anterior en los síntomas más significativos de la etapa de transición entre la que denomino "zarzuela isabelina" (1848-ca. 1868) y lo que sucedería después de ella, singularmente a partir de la década de los sesenta ${ }^{32}$ : el estreno en 1864 en el Teatro de la Zarzuela de la primera opereta de Jacques Offenbach adaptada al castellano como zarzuela: Los dioses del Olimpo; la definitiva consagración de la senda bufa (la opereta española) con el éxito popular de la empresa de los Bufos Madrileños desde 1866; el simbólico concurso de óperas españolas de 1869 promovido por Bonifacio Eslava, Antonio Romero, Aquiles Di Franco y Emilio Arrieta; la llegada de una nueva generación de creadores e intérpretes; y por último, el tema sobre el que profundizaremos a continuación: la aparición de un nuevo público que determina la proliferación de los cafés-teatros y, en consecuencia, del teatro por horas.

Esta metamorfosis de las estructuras sociales y estéticas de la zarzuela durante los años sesenta del siglo XIX se produjo en paralelo a una profunda crisis económica, política y sociocultural durante el último periodo del reinado de Isabel II. Durante el lustro que media entre 1863 y 1868, con la alternancia en el poder entre el reaccionarismo del Partido Moderado y el conservadurismo de la Unión Liberal, existía en Madrid una pequeña burguesía en crecimiento que, frente a la alta burguesía firmemente conservadora política y socialmente, iría radicalizándose contra el régimen consagrado por la constitución de $1845^{33}$. Tras la hambruna y el restablecimiento de los consumos en 1857 el malestar de esta pequeña burguesía fuera de juego iría in crescendo azuzado por escándalos como la Noche de San Daniel en $1865^{34}$, la sangrienta represión de las intentonas golpistas de 1866, la crisis financiera que se iniciaría ese mismo año, la epidemia de cólera en Madrid de 1867, etc. A pesar de todo, esta incipiente clase media urbana, constituida por funcionarios, militares en servicio, de reemplazo y retirados, propietarios, arrendadores, comerciantes, fabricantes e industriales ${ }^{35}$, deseaba divertirse en su tiempo libre de trabajo

${ }^{31}$ E. Mejías García: "La pionera historia de la zarzuela de Martín Sánchez Allú en la encrucijada estética e ideológica de la zarzuela isabelina", Revista de Musicología, vol. 38, n. ${ }^{2}$ 2, pp. 529-560.

32 E. Mejías García: "Cuestión de géneros...", pp. 28-31.

33 Miguel Beltrán Villalva: Burguesía y liberalismo en la España del siglo XIX. Sociología de una dominación de clase, Granada, Universidad de Granada, 2010, pp. 178 y ss; Jesús Cruz Valenciano: Los notables de Madrid. Las bases sociales de la revolución liberal española, Madrid, Alianza, 2000.

${ }^{34}$ El 10 de abril de 1865, el Ejército y la Guardia Civil reprimieron sangrientamente a los estudiantes de la Universidad Central de Madrid congregados en la Puerta del Sol para apoyar al rector de la misma. Este había sido depuesto días antes por negarse a acatar la orden del gobierno de Narváez que destituía al catedrático Emilio Castelar, tras haber publicado estos dos artículos muy críticos con la reina Isabel II.

35 Tabla "Profesiones", Anuario administrativo y estadístico de la provincia de Madrid para el año 1868, Madrid, Diputación Provincial, 1868, p. 71. 
ocupando una parcela del espacio público en el que, desde luego, el teatro jugaba un papel fundamental: "Como en otros lugares de Europa, a mediados del siglo XIX los públicos urbanos con niveles adquisitivos medios y bajos pudieron empezar a sostener en España una rudimentaria industria del entretenimiento paralela a otra más escogida y costosa cuya razón de ser estaba nada más que en procurar diversión"36.

En este sentido es inevitable referirse a Jürgen Habermas y a su visión de la transformación de la esfera pública a lo largo del siglo XIX, en relación con la irrupción de las masas en los ámbitos de la vida social hasta entonces reservados a la burguesía. En palabras de Habermas: “[...] desde mediados del siglo XIX se transforman las instituciones que constituían hasta entonces el marco del público raciocinante" ${ }^{37}$. Como desarrollaremos más abajo, la idea de seccionar la arcaica y extensa función teatral en sesiones, con el consecuente abaratamiento de las entradas, podría entenderse dentro de lo que Habermas denomina como funciones del mercado que facilitan económica y psicológicamente el acceso a una cultura de masas, lo que, a su vez, llevaría a mercantilizar no solo la forma, sino también el contenido de la cultura ${ }^{38}$. Para el caso español no se trataría de un fenómeno aislado, ya que en el ámbito del toreo también en la década de los años sesenta del siglo XIX se inician una serie de procesos que conducirían a esta forma de ocio de masas hacia lo que Adrian Shubert ha entendido como una auténtica y bien asentada industria cultural al inicio de la "era de las diversiones públicas"39.

En referencia al espectáculo de zarzuela, se suele insistir en su cariz protodemocrático o popular desde el éxito de Jugar con fuego en 1851 en adelante. Clinton D. Young ha afirmado taxativamente que "la aristocracia apoyaba la ópera italiana pero el pueblo español acudía a las representaciones de zarzuelas" ${ }^{40}$. Sin embargo, aunque la diferencia de precio de los abonos a palcos y plateas entre el Teatro Real y los teatros de zarzuela en torno a 1850 era considerable, entre butacas y paraíso las diferencias no eran tan acusadas ${ }^{41}$. En otras palabras: el Teatro Real no podía ser frecuentado por la

\footnotetext{
${ }^{36}$ D. Castro: "Tipos y aires...", p. 81.

37 Jürgen Habermas: Historia y crítica de la opinión pública, Antonio Doménech y Rafael Grasa (trad.). México, Gustavo Gili, 1986 (3ª ed.), p. 191.

38 J. Habermas: Historia y crítica de la opinión pública..., p. 194.

39 Adrian Shubert: A las cinco de la tarde. Una historia social del toreo, Benito Espinosa (trad.). Madrid,

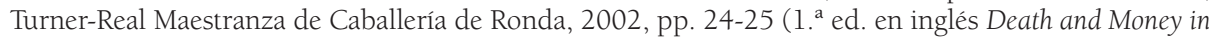
the Afternoon. A History of the Spanish Bullfight, Nueva York, Oxford, Oxford University Press, 1999).

${ }^{40}$ C. D. Young: Music Theatre and Popular Nationalism in Spain..., p. 8: "The aristocracy supported Italian opera, but the Spanish people attended performances of zarzuela". Todas las traducciones son nuestras.

${ }^{41}$ D. Castro: "Tipos y aires...", p. 70. Esta alianza o fusión entre la aristocracia y la alta burguesía no era, en ningún caso, exclusiva de Madrid. Para los conciertos públicos de música instrumental véanse los casos de Londres, París o Viena estudiados por William Weber: Music and the Middle Class. The Social Structure of Concert Life in London, Paris and Vienna, Nueva York, Holms and Meier, 1976.
} 
"gran pequeña burguesía”, pero el Circo o la Zarzuela tampoco podían ser frecuentados por el pueblo bajo. Citando de nuevo a Demetrio Castro: "El teatro en general, y el lírico entre él, resultaba, a mediados de siglo inasequible como forma de ocio regular para la población trabajadora asalariada, situación que cambiaría con el arraigo del teatro por horas y el género chico durante la Restauración" 42 . Sin embargo, lo que aquí nos preguntamos es si esa "gran pequeña burguesía" realmente hubo de esperar tanto, hasta la Restauración.

Según el Anuario administrativo y estadístico de la provincia de Madrid para el año $1868^{43}$, pocos meses antes de la Revolución, una Villa y Corte de cerca de 283.000 habitantes contaba con, además de tres salones de baile, circos, plaza de toros, el jardín de los Campos Elíseos, juegos de pelota y varios casinos, dieciséis teatros, de los cuales seis se dedicaban al género líricodramático, es decir, a la zarzuela. Considerados como de primer orden o de primera categoría eran los Bufos ${ }^{44}$, la Zarzuela y Novedades; de tercer orden,Variedades; de cuarto orden, la Esmeralda y la Infantil. Es interesante señalar que para 1868 no existían en Madrid teatros de segundo orden, ejemplo de la polarización social de la época que nos obliga a cuestionar cualquier noción de clase media reconocible por entonces como tal.A estas salas tendríamos que sumar los cafés-teatros ${ }^{45}$, que ese mismo año eran -oficialmente- quince, tres de ellos dedicados también a la zarzuela: el de Marsella, el de la Amistad y el de Novedades, en la finca del teatro del mismo nombre. En las siguientes tablas sintetizamos esta información ordenando el listado de salas por categoría y aforo.

\footnotetext{
42 D. Castro: "Tipos y aires...", p. 60.

${ }^{43}$ Anuario administrativo y estadístico de la provincia de Madrid para el año 1868, Madrid, Diputación Provincial, 1868. De este anuario extraemos todos los datos estadísticos siguientes.

${ }^{44}$ Ubicados por entonces en el Teatro del Circo de la Plaza del Rey.

45 Sobre el café-teatro en el Madrid del siglo XIX resultan de obligada lectura los artículos de Alberto Castilla: "Cómo surgieron los cafés-teatro de Madrid. El teatro en la Revolución de Septiembre", Tiempo de Historia, n. ${ }^{3}$ 4, 1-9-1977, pp. 60-71; Mercedes Agulló y Cobo: "Los cafés-teatros madrileños del siglo XIX", Villa de Madrid, n. ${ }^{\circ}$ 35-36, 1972, vol. II y III, pp. 27-32.
} 
Cuadro 1. Teatros públicos de Madrid a 28 de febrero de 1868 (Fuente: Anuario administrativo y estadístico de la provincia de Madrid para el año 1868)

\begin{tabular}{|c|c|c|c|}
\hline & Género de espectáculos & Orden a que pertenece & Número de localidades \\
\hline Rossini & Líricos & $1 .^{\circ}$ & 2.570 \\
\hline Teatro Real & Ópera italiana & $1 .^{\circ}$ & 2.404 \\
\hline Los Bufos & Ĺricos & $1 .^{\circ}$ & 2.148 \\
\hline Novedades & Lírico-dramáticos & $1 .^{\circ}$ & 1.778 \\
\hline La Zarzuela & Lírico-dramáticos & $1 .^{\circ}$ & 1.766 \\
\hline Príncipe & Dramáticos & $1 .^{\circ}$ & 1.358 \\
\hline Variedades & Lírico-dramáticos & $3 .^{\circ}$ & 700 \\
\hline Capellanes & Declamación y bailes & $3 .^{\circ}$ & 700 \\
\hline Buena-Vista & Dramáticos & $3 .^{\circ}$ & 200 \\
\hline Máiquez & Declamación y bailes & $3 .^{\circ}$ & 200 \\
\hline Quevedo & Dramáticos & $3 .^{\circ}$ & 400 \\
\hline De Paul & Baile & $3 .^{\circ}$ & 285 \\
\hline La Infantil & Lírico-dramáticos & $4 .^{\circ}$ & 260 \\
\hline Las Musas & Dramáticos & $4 .^{\circ}$ & 150 \\
\hline La Esmeralda & Lírico-dramáticos & $4 .^{\circ}$ & \\
\hline Tabernillas & Dramáticos & $4 .^{\circ}$ & \\
\hline
\end{tabular}

Cuadro 2. Cafés-teatros de Madrid a 28 de febrero de 1868 (Fuente: Anuario administrativo y estadístico de la provincia de Madrid para el año 1868)

\begin{tabular}{|c|c|c|c|}
\hline & Género de espectáculos & Orden a que pertenece & Número de localidades \\
\hline El Recreo & Dramáticos & $3 .^{\circ}$ & 700 \\
\hline San Marcial & Dramáticos & $3 .^{\circ}$ & 200 \\
\hline De Marsella & Lírico-dramáticos & $4 .^{\circ}$ & 700 \\
\hline Lozoya & Dramáticos & $4 .^{\circ}$ & 150 \\
\hline Calderón de la Barca & Dramáticos & $4 .^{\circ}$ & 150 \\
\hline De Embajadores & Dramáticos & $4 .^{\circ}$ & 150 \\
\hline San Fernando & Dramáticos & $4 .^{\circ}$ & 150 \\
\hline La Industria & Lírico-Dramáticos & $4 .^{\circ}$ & 140 \\
\hline Maravillas & Dramáticos & $4 .^{\circ}$ & 100 \\
\hline Artistas & Dramáticos & $4^{\circ}$ & 100 \\
\hline San Francisco & Dramáticos & Último $^{\circ}$ & 160 \\
\hline La España & Dramáticos & Último & 120 \\
\hline Novedades & Lírico-Dramáticos & Último & 60 \\
\hline De la Amistad & Lírico-Dramáticos & Último & $\dot{e}^{\text {? }}$ \\
\hline Del Sur & Dramáticos & Último & ¿? \\
\hline
\end{tabular}


En nuestra opinión, es en estos cafés-teatros (todos de tercer, cuarto y último orden) y por supuesto también en los teatros de tercera y cuarta como Variedades y la Infantil donde se refugiaba esa pequeña burguesía, antes citada, ávida de zarzuela. Es fácil comprender que la zarzuela sí pudo "popularizarse" más en estas salas -las que prácticamente no aparecen en las carteleras de los periódicos ${ }^{46}$ - y no tanto en las para-aristocráticas de los Bufos, la Zarzuela o Novedades, consideradas, como hemos dicho, de primer orden, al mismo nivel que el Real o el Rossini de los Campos Elíseos. Por entonces, se decía que en Madrid había “un sinnúmero de cafés donde se representa y se canta que es una bendición de Dios" ${ }^{47}$, o más mordazmente:

Hoy entra Vd. en un café y por un par de reales le dan una taza de café, una jícara de chocolate o un sorbete, en fin, lo queVd. pida, y además dos o tres zarzuelas con música y todo, o un drama con traidor [...] En otro tiempo, algunos cafés tenían la costumbre de regalar al consumidor un dulce seco o un pilón de azúcar; hoy, en lugar de eso, dan un drama o una zarzuela ${ }^{48}$.

Según alguna "gacetilla” en la prensa histórica, para 1859 no existían todavía en Madrid establecimientos de café-teatro, café-cantante o caféconcierto (de las tres maneras se denominaban inicialmente) ${ }^{49}$. El historiador Carlos Cambronero, sin embargo, en su crónica clásica sobre el Madrid de los tiempos de Isabel II insistiría en que hacia el verano de 1850 "se generalizó la costumbre de dar conciertos en los cafés para atraer concurrencia" ${ }_{50}$ citando, entre otros, el de Neptuno, el de la Plaza del Progreso, el Español o el de Amato. Gracias a las investigaciones de José Blas Vega sabemos que al menos desde los años treinta del siglo XIX en establecimientos como el Café de Cervantes se organizaban bailes de máscaras en Carnaval y conciertos $^{51}$. En la primera década del siglo XIX un antecedentes de esta clase de cafés-conciertos podría localizarse en la Fonda y Café de la Cruz de Malta, fundada en el siglo XVIII y que, según Mesonero Romanos, conservó su "primitivo carácter de café cantante” en el que se leían versos patrióticos “en medio de los dúos y cavatinas" 52 . En este sentido, el fenómeno de los cafés-conciertos de Madrid al mediar el siglo,

\footnotetext{
${ }^{46}$ La programación de los cafés-teatros y de los teatros de tercera y cuarta categoría se anunciaba, normalmente, con carteles en la vía pública. Léase al respecto el artículo de Luis Rivera: "Lo que corre por ahî", Gil Blas, 28-3-1867, p. 1.

47 Juan Pedro Pérez: "Cartas [...]", El Artista, 15-6-1868, p. 11.

${ }^{48}$ Eladio Lezama: "Lo que corre por ahí / Los cafés", Gil Blas, 21-2-1867, p. 1.

49 J. Villar: "Gacetilla", La Esperanza, 3-1-1859, p. [4]; "Gacetillas", La Discusión, 29-3-1859, p. [4].

50 Carlos Cambronero: Crónicas del tiempo de Isabel II, Madrid, La España Moderna, [1913], p. 229. 38 y ss.

${ }^{51}$ José Blas Vega: Los cafés cantantes de Madrid (1846-1936), Madrid, Guillermo Blázquez, 2006, pp.

52 Ramón de Mesonero Romanos: Memorias de un setentón, natural y vecino de Madrid, Tomo I (18081823), Madrid, Oficinas de "La Ilustración Española y Americana", 1881, p. 225.
} 
si bien algo tardío, no es muy distinto del de otras capitales como Londres o París y podríamos alinearlo, siguiendo a Tim Blanning, junto a otros fenómenos culturales definitorios del mundo moderno que hundían sus raíces en un largo siglo XVIII como la fundación de museos y bibliotecas públicas o el nacimiento del periodismo, la crítica y la novela moderna ${ }^{53}$.

Todavía en 1860, cuando se anunciaba que el Café de Capellanes iba a habilitarse como "café lírico o caffé chantant" [sic] se señalaba que "gran falta hacía en la corte un establecimiento de esta clase" 54 a la manera del Café de l'Eldorado de París, abierto en 1858. La ansiada inauguración tuvo lugar a comienzos de 1861 describiéndose por entonces "un pequeño teatro [...] donde alternando con escogidas piezas de música, se cantan trozos de ópera y de zarzuelas" 55 . En Capellanes, que entonces llegó a denominarse Café Lírico $^{56}$, se ofrecían dos funciones al día, con el abaratamiento consecuente de las entradas: "de manera que, con solo hacer un pequeño gasto, se pueden pasar un par de horas agradables" "57. A finales de 1860 también se había adaptado el café de Colón como "café cantante" en el que se cantaban "piezas de ópera italiana y [...] otras de las zarzuelas más acreditadas" 58.

El éxito de Capellanes en 1861 con su teatrillo y orquesta ${ }^{59}$ debió ser muy notable. A imitación de él, a lo largo del siguiente lustro, otros cafés de Madrid iniciaron reformas de acondicionamiento de sus instalaciones como testimoniaría el escritor Julio Nombela desde su tribuna en La Época en el verano de 1867:

Al desaparecer el café cantante, como se llamó al que había en Capellanes, fueron naciendo aquí y allá, primero en los barrios apartados y luego hasta en los del centro, una porción de cafés-teatros, los cuales, dominados por el espíritu de hipocresía que caracteriza a nuestra época, aspiraron a servir de honesto recreo, de amena distracción a los que antes se pasaban las horas muertas al lado de una taza de café arreglando la cosa pública o murmurando del prójimo ${ }^{60}$.

\section{El Café-teatro del Recreo: la confirmación de un mito}

De entre todos los cafés-teatros posteriores al éxito del Lírico de Capellanes, debemos detenernos en el Recreo, espacio que ha quedado señalado en la historiografía como primer lugar en el que se ensaya en Madrid el

53 Timothy C. W. Blanning: The Culture of Power and the Power of Culture: Old Regime Europe, 16691789, Oxford-Nueva York, Oxford University Press, 2002, p. 2.

54 "Noticias generales", La Época, 19-9-1860, p. [4].

55 "De Madrid", La España, 19-3-1861, p. [4].

56 "Gacetilla de la capital", El Contemporáneo, 4-5-1861, p. [4]

57 Ídem. La información sobre las dos funciones la ofrece Mercedes Agulló y Cobo: op. cit., p. 30.

58 "Café cantante", La Iberia, 29-11-1860, p. [1].

59 "Gacetillas de la capital", El Observador, 4-5-1861, p. [4].

60 Julio Nombela: "Misterios de Madrid", La Época, 6-8-1867, p. [4]. Las cursivas son del autor. 
sistema del teatro por horas ${ }^{61}$. La excepcional importancia que se ha dado a este local de la calle de la Flor Baja tal vez tenga que ver con que fuese el primer café-teatro del que se publicaron carteleras (aunque no de manera regular) en la prensa diaria madrileña. Igualmente, es muy probable que fuese el primer café en el que se ofreciesen funciones teatrales completas y no solo conciertos, a causa, precisamente, de la singularidad de su arquitectura.

Gracias a los periódicos sabemos que el Recreo -a diferencia de Capellanes- fue primero un teatro con salón de baile al que se añadió finalmente en 1863 un café con confitería ${ }^{62}$. Desde ese año hasta 1866 en el Recreo, principalmente, se anunciaron bailes de máscaras de sociedades recreativas como El ramillete o El guante de oro. En su teatro se programaban ocasionalmente funciones navideñas con la tradicional escenificación del Nacimiento y dramas bíblicos precedidos de sinfonías y comedias breves, zarzuelas y tonadillas como finales de fiesta.Además de un espacio habilitado para una orquesta, por el tipo de obras programadas podemos deducir que el Teatro del Recreo -con 700 localidades según las estadísticas de 1868- contaba con una considerable equipación técnica y un escenario comparable al del Teatro Variedades ${ }^{63}$. No de otra manera podemos entender que a comienzos de 1866 se anunciasen dos funciones diarias de la comedia en cinco actos titulada La toma de Argel por los franceses que se presentaba con "diez decoraciones enteramente nuevas, todas de gran aparato" 64 .

Finalmente, en abril de 1866 se reformula el modelo de negocio del Recreo al que -como hemos dicho- tres años antes se había añadido la cafetería y confitería. Pasa a anunciarse como café-teatro, es decir, justo lo contrario: un café que ofrece la atracción de las representaciones escénicas. De las dos funciones de La toma de Argel a comienzos de año pasamos a cuatro, señalándose que "el consumo que se haga de un real en adelante da derecho a una función" ${ }^{65}$ : "Dicho establecimiento ofrece la particularidad que se diferencia de los demás de su clase de tener dos salones, uno destinado a las funciones dramáticas y otro para los consumidores. Estos pueden optar a un billete del teatro haciendo el módico gasto de un real y medio" 66 .

Sin embargo, el propio Nombela señalaría un año más tarde, cuando la moda del café-teatro se hallaba en su cénit, que el modelo del Café del Recreo no era, desde luego, el preferido del público:

${ }^{61}$ No debe confundirse este Café del Recreo con el homónimo que existió décadas antes en la calle de Alcalá.

${ }^{62}$ Diario Oficial de Avisos de Madrid, 14-9-1863, p. [2].

63 J. Nombela: "Revista de teatros", La Época, 13-3-1866, p. [1].

${ }^{64}$ La Correspondencia de España, 28-1-1866, p. [3]. En algunos medios se anuncia la obra con el título de La conquista de Argel.

65 "Espectáculos", La Discusión, 3-5-1866, p. [3].

66 "Todo se esplota" [sic], La España, 7-11-1866, p. [3]. 
Hay dos clases de cafés-teatros: en los unos está el escenario colocado de modo que todos los parroquianos pueden ver la función desde sus asientos o ir pasando las comedias a tragos. En los otros, el teatro es independiente del café y los parroquianos adquieren el derecho de entrar a ver un acto por cada taza de café o vaso de leche merengada que consumen. Los primero son los más populares, los más favorecidos del público ${ }^{67}$.

El Recreo debió ser el café-teatro más lujoso de los conocidos hasta la fecha en Madrid, contando, además, con dos compañías, una lírica y otra dramática $^{68}$. Del extraordinario éxito de su propuesta da cuenta que en 1867 se hiciese necesaria una reforma completa del espacio teatral ${ }^{69}$. Aunque sabemos que en su caso y en el de Capellanes sí se contaba con orquesta, lo cierto es que carecemos de documentación sobre el tipo de agrupaciones instrumentales de los demás cafés-teatros de esta época. En no pocos testimonios históricos se cita, eso sí, la frecuente interpretación de zarzuelas acompañadas por reducciones pianísticas, como por ejemplo este de Francisco Flores García en sus memorias teatrales:

En el café de El Vapor, que estaba situado en la calle de Hortaleza, esquina a la de las Infantas, actuaba una compañía de zarzuela, cuyo presupuesto, incluyendo la orquesta (léase piano), ascendía a la respetable suma de ochenta y dos reales diarios. El juramento era lo mejor que interpretaba aquella compañía, pasando con frecuencia y con facilidad del juramento a la blasfemia ${ }^{70}$.

Sobre el tipo de actores y cantantes de estas obras, sabemos por Julio Nombela que en su mayoría eran debutantes, artistas poco conocidos y jóvenes que todavía estudiaban en el conservatorio. Esto no quiere decir que las interpretaciones dejasen que desear, pues de la compañía cómico-lírica del Recreo se dijo que era "muy regular y superior a las que suelen actuar en muchos teatros de provincias" 71 . Gracias a la prensa conocemos los nombres de algunos de estos artistas precursores del Recreo: el barítono Sr. Ortiz, la actriz Srta.Torres, los actores Sres. Guarte y Juárez Iglesias. Los tan repetidos nombres de los pioneros del teatro por horas en Madrid, Antonio Riquelme, José Vallés y Juan José Luján, no los hemos localizado en ninguna referencia al Café del Recreo o del Lozoya (que son los que se suelen citar) hasta 1869. En agosto de ese año se les anuncia junto a Andrés

\footnotetext{
67 J. Nombela: "Misterios de Madrid...".

68 "Inauguración", La Discusión, 3-5-1866, p. [3].

69 Ángel Luis Fernández Muñoz: Arquitectura teatral en Madrid, Madrid, Ayuntamiento de Madrid, El Avapiés, 1989, pp. 235-236.

70 Francisco Flores García ("Córcholis"): Memorias intimas del teatro, Valencia, F. Sempere y Compañía, s. f., p. 78. Se refiere a El juramento: zarzuela en tres actos de Luis de Olona, música de Joaquín Gaztambide (Teatro de la Zarzuela, 1858).

71 "Gacetillas / Inauguración", La Discusión, 29-4-1866, p. [3].
} 
Ruesga entre los artistas que formaban la compañía del Teatro del Recreo y que, a partir de septiembre, pasaría al Teatro de Variedades, convirtiéndose desde entonces en un teatro por horas con servicio de cafép ${ }^{72}$.

Como era de esperar, desde la primera cartelera anunciada el 1 de mayo de 1866 la zarzuela hizo las delicias de los parroquianos del Recreo junto a los productos de su confitería y café: dos títulos populares como eran Un caballero particular ${ }^{73}$ y El grumete $^{74}$ se programaron junto a la comedia Cero y van dos ${ }^{75}$. Las tres obras eran de repertorio, estrenadas en teatros de primer orden durante la década anterior, con el comprensible interés de ese gran público que citábamos arriba que probablemente no había podido disfrutar regularmente de ellas. Se trataba, por tanto, de un formato de producción teatral estrechamente vinculado a una nueva sociabilidad en el teatro; una nueva manera de entender el espectáculo acorde con el gran público que no podía acudir con regularidad a los teatros de primer orden. En prensa se llega a hablar de "pueblo" en referencia al público del Recreo:

Este establecimiento continúa favorecido todas las noches por un público tan numeroso como lo permite el local. Los actores que trabajan en el pequeño teatro del mismo se esmeran mucho en la ejecución de cuantas piezas cómicas y cómico-líricas ponen en escena [...]. Aplaudimos sinceramente la idea de llevar el teatro a los cafés, pues de esta manera esos establecimientos que hasta hoy han sido destinados a cierto género de expansiones, pueden ejercer de hoy más notable y provechosa influencia en las costumbres del pueblo ${ }^{76}$.

A excepción de El grumete, las zarzuelas programadas en el Recreo como El amor y el almuerzo $0^{77}$ y El último mono ${ }^{78}$ no tenían parte coral y además todas ellas eran de temática meramente bufa/cómica. No forman parte, por tanto, del repertorio paraoperístico a la manera de Jugar con fuego, que dotó de buena reputación a la zarzuela isabelina entre la crítica, sino, más bien, del primer grupo de obras de lo que considero la "opereta española”, en concomitancia con el tipo de teatro cómico-lírico desarrollado durante

\footnotetext{
72 "Gacetillas / Variedades", La Discusión, 31-8-1869, p. [3].

${ }^{73}$ Un caballero particular: juguete cómico-lírico en 1 acto de Carlos Frontaura, música de Francisco Asenjo Barbieri (Teatro de la Zarzuela, 1858). Todos los teatros de las obras referenciadas son de Madrid.

${ }^{74}$ El grumete: zarzuela en 1 acto de Antonio García Gutiérrez, música de Emilio Arrieta (Teatro del Circo, 1853).

${ }^{75}$ Cero y van dos: juguete cómico en 1 acto de Juan de Coupigny (Teatro del Príncipe, 1851).

76 "Gacetillas / Café-teatro del Recreo", La Discusión, 3-5-1866, p. [3].

${ }^{77}$ El amor y el almuerzo: farsa en 1 acto arreglada del francés por Luis Olona, música de Joaquín Gaztambide (Teatro del Circo, 1856).

${ }^{78}$ El último mono: sainete filosófico escrito en verso sobre un pensamiento de [Jean-Baptiste Alphonse] Karr en 1 acto de Narciso Serra, música de Cristóbal Oudrid (Teatro de la Zarzuela, 1859).
} 
esos mismos años en Francia ${ }^{79}$. No por casualidad en la revista de actualidades 1866 y $1867^{\circ 0}$ de José María Gutiérrez de Alba (estrenada a finales de 1866) la personificación alegórica del Recreo aparecería vestida de "arlequín con organillo y cafetera”, en referencia al carácter bufo de las obras representadas en este espacio y a lo popular de su ambiente (de ahí la presencia del organillo, antítesis del arpa, la lira o el violín).

En el Café-teatro del Recreo ya encontramos un espacio público de representación teatral donde en torno a 2.800 personas diarias (multiplicando su aforo por las cuatro funciones consabidas) podían acudir a divertirse viendo la obra, consumiendo en el café y no tanto para establecer relaciones poniendo de manifiesto el propio estatus socioeconómico en palcos y foyers, que era la principal función social que cumplían los teatros de primera categoría herederos de ciertas prácticas aristocráticas más propias del Antiguo Régimen ${ }^{81}$. En este sentido, Harold Love ha insistido en desmitificar esa idea del café como espacio de encuentro, tertulia o discusión entre personas con puntos de vista diferentes: "En esencia eran lugares donde uno acudía para evitar encontrarse con personas con las cuales se podría estar en desacuerdo"s2.

Regresando al testimonio de Julio Nombela podríamos confirmar este nuevo sentir sin duda más moderno y contemporáneo de la sociabilidad en el café-teatro cuando da la palabra al dueño de uno de estos establecimientos diciéndonos:

-Ya ve usted -me dijo el dueño-: ¿quién por un par de reales no se pasa una noche divertida?... Y lo que dicen los parroquianos: mejor es venir aquí que ir al teatro; allí cuesta todo más caro y no pueden rechistar, no hablan en los entreactos con los actores y los de la manga verde no les dejan fumar. Aquí están todos como en familia... y crea usted que si no fuera por los autores, que me llevan diez reales por cada pieza que represento, esto sería un negocio. La compañía me cuesta cincuenta o sesenta reales con el pianista y todo [...].

Pocos días después oí en una reunión de confianza una conversación sobre los cafés-teatros:

- Por mi parte - decía una señora-, voy con más gusto al café que al teatro.

- Tiene usted razón, la cuestión es distraerse, y lo mismo se ve una comedia en el teatro que en el café.

- Lo mejor que hay es que no tiene una que vestirse $[\ldots]^{83}$.

${ }^{79}$ Enrique Mejías García: "Cuestión de géneros...”, p. 35.

801866 y 1867: revista en dos cuadros y en verso original de Don José María Gutiérrez de Alba, música de Cristóbal Oudrid y Luis Vicente Arche (Teatro del Circo, 1866).

${ }^{81}$ Por su vivacidad en la pintura de tipos y el ambiente de "un café-teatro en uno de los barrios más apartados del centro de la capital" en el que se representan dramas románticos y se juega al bingo y al billar, no podemos dejar de recomendar la lectura del sainete original y en verso de Tomás Luceño: El teatro moderno, Madrid, Imp. Española, 1871.

82 Harold Love: "How Music Created a Public", Criticism, vol. 46, n. ${ }^{2}$, primavera 2004, p. 258. "In essence, these were places one went to in order to avoid meeting people who might disagree with one".

83 J. Nombela: "Misterios de Madrid...". 
Un año antes de la autorización legal de las representaciones teatrales en los cafés-cantantes de París ${ }^{84}$ (31 de marzo de 1867), la asistencia en Madrid al café-teatro en 1866 ya garantizaba una nueva forma de ocio bien avenida con esa sociedad decididamente protodemocrática cuyos intereses se pondrían en el centro del tablero del juego políticomilitar dos años después durante la Gloriosa. Cuatro eran las ventajas que ofrecía, por tanto, el café-teatro a sus espectadores: lo económico de su precio, la informalidad social del espacio/evento, la programación de obras tan populares como puramente "divertidas" y una nueva manera de entender el espectáculo y sus tiempos conciliables con la jornada laboral: el teatro por horas.

\section{"En esos teatros donde se ven actos solos..."}

Como se ha visto más arriba, la primera cartelera publicada del Recreo solo especificaba tres funciones, pero lo cierto es que a los pocos días ya se establecieron las cuatro de rigor. Es en este contexto en el que podemos empezar a hablar claramente de un teatro por horas en Madrid desde 1866, anunciándose funciones regulares a las 20:30, 21:30, 22:30 y 23:30. Estas obras habían sido estrenadas años antes en teatros como el Circo o la Zarzuela en funciones únicas que se completaban con otros títulos hasta llegar a los tres o cuatro actos de representación. Por ejemplo, cuando se estrenó El grumete el 17 de junio de 1853 el cartel del Teatro del Circo se conformó de la siguiente manera:

A las 21:00

$1 .^{\circ}$ - Sinfonía

2. ${ }^{\circ}$ - Acto segundo de la zarzuela El sueño de una noche de verano ${ }^{85}$

$3 .{ }^{\circ}$ - Miscelánea del jarabe americano (baile)

4. ${ }^{\circ}-$ El grumete

$5 .^{\circ}$ - Baile nacional

Otro buen ejemplo sería el del estreno el 30 de mayo de 1859 de El último mono en una función conformada por cuatro zarzuelas breves, lo que hoy podríamos denominar un auténtico programa cuádruple:

${ }^{84}$ Para profundizar en los contextos contemporáneos del café-teatro en Francia resultan de fundamental lectura los trabajos de Martin Pénet: "Le café-concert, un nouveau divertissement populaire" y Catherine Savev: "Le café-concert: un théâtre parallèle", Les spectacles sous le Second Empire, Jean-Claude Yon (dir.), París, Armand Colin, 2010, pp. 349-365 y 366-383.

${ }^{85} \mathrm{El}$ sueño de una noche de verano: ópera cómica en tres actos escrita en francés por los señores Rosier y de Leuven, libremente traducida al castellano por [Patricio de la Escosura], música de Joaquín Gaztambide (Teatro del Circo, 1852). 
A las 20:30

$1^{\circ}$ - Frasquito 86

$2 .^{\circ}-$ iUn cocinero ${ }^{87}$

3. ${ }^{\circ}$ - El último mono

4. ${ }^{\circ}$ - Las cábalas de Basilio ${ }^{88}$

A todas luces, el público que en general optaba por acudir al café-teatro carecía no solo de tanto dinero para la entrada, sino también de tanto tiempo libre. En este sentido, debemos volver a citar a Julio Nombela en cuyo artículo de costumbres de 1867 sobre el café-teatro se afirmaba: "Lo que más me gusta a mí - dijo un caballero terciando en la conversación- es que en esos teatros donde se ven actos solos entra uno, y si hacen una cosa que agrada, vuelve uno a entrar, y si no se marcha, mientras que en el teatro le hacen a uno tragarse toda la función" 89.

En relación a esta idea de explotación "por actos solos" debemos significar una noticia tal vez inadvertida en su momento pero de indudable interés historiográfico para nosotros. A finales de 1866 se anunciaba:

Se ha establecido un nuevo teatro en el café de Occidente de la Carrera de San Francisco, el cual se dedica especialmente a la representación de comedias y piezas nuevas y originales escritas ad hoc. El sábado último se puso en escena un juguete titulado: Soltero y casado y se preparan, entre otras obras, Las catacumbas de Chinchón, Escenas de actualidad, El tío Gilí y una revista ${ }^{90}$.

Tal vez sea este primer repertorio ad hoc para "cafés-teatro por horas" el verdadero origen del que posteriormente sería ... denominado como género chico... y del que nos ocuparemos más abajo. Por desgracia, no se conservan apenas fuentes de estas primeras obras que incluso se estrenaron sin pasar censura previa ${ }^{91}$. Sin embargo, las carteleras indican que en los cafés-

${ }^{86}$ Frasquito: zarzuela en 1 acto arreglada al teatro español por Ricardo de la Vega, música de Manuel Fernández Caballero (Teatro de la Zarzuela, 1859).

${ }^{87}$ iUn cocinero!: zarzuela en 1 acto y en verso arreglada a nuestro teatro por Francisco Camprodón, música de Manuel Fernández Caballero (Teatro de la Zarzuela, 1858).

${ }^{88}$ Las cábalas de Basilio: según la prensa era un juguete cómico-lírico en 1 acto cuyo autor no fue anunciado (permaneció apenas dos días en cartel). Barbieri sí informa del nombre del compositor de la música: Rafael Taboada. La obra se estrenaba el mismo día que El último mono.

${ }^{89}$ J. Nombela: "Misterios de Madrid...".

90 "Segunda edición", La Correspondencia de España, 28-12-1866, p. [3]. Entendemos que Soltero y casado, por tanto, nada tiene que ver con la zarzuela Casado y soltero (1858) de Luis de Olona, con música de Joaquín Gaztambide.

${ }^{91}$ De estos títulos anunciados para el café de Occidente ninguno consta en el índice de Vicente de Lalama (ni en sus suplementos de 1868 y 1872): Índice general por orden alfabético de cuantas obras dramáticas y líricas han sido aprobadas por la junta de censura y censores de oficio, para todos los teatros del reino y de ultramar, comprendiendo los años de 1850 a 1866: precedido de los decretos sobre propiedad literaria, orgánico de teatros y cuantas reales órdenes se han expedido sobre la misma materia, así como los tratados internacionales verificados con las naciones extranjeras, Pinto, Imp. de G. Alhambra, 1867. 
teatros se prefería programar obras de repertorio. Por ejemplo, de vuelta a Capellanes (anunciado en prensa desde marzo de 1867 como Gran caféteatro de Capellanes) había cuatro o cinco funciones diarias con casi el mismo repertorio que meses antes se programaba en el Recreo, como La casa de campo ${ }^{92}$ o Es una malva93. El éxito de esta nueva etapa de Capellanes animaría a la empresa a anunciarlo a la vuelta del verano de 1867 como teatro-café y finalmente como reformado Teatro Alarcón a comienzos de 1868. En esta sala se programarían, cómo no, zarzuelas, todas ellas de repertorio: Una vieja ${ }^{94}$ El amor y el almuerzo, El último mono, Un caballero particular, e incluso reposiciones de comedias seccionadas por actos, como por ejemplo la que encontramos en el cartel del 27 de abril de 1867:

\section{0:30 - La cruz del matrimonio ${ }^{95}$ (primer acto) \\ 21:30 - La cruz del matrimonio (segundo acto) \\ 22:30 - La cruz del matrimonio (tercer acto) \\ 23:30 - Sálvese el que pueda ${ }^{96}$}

\section{Del café al teatro: la revolución de los teatros por horas}

El gusto abusivo por las zarzuelas de repertorio en los cafés-teatros, ajeno a todo control de galeristas y empresarios teatrales, obligó a finales de 1867 a legislar sobre el asunto promulgándose una repentina prohibición por Real Orden que contradecía el régimen previo de libertad y no-censura o la ya citada autorización en Francia para las representaciones teatrales en los cafés en marzo de ese año:

En vista de la instancia remitida porV. E. a este Ministerio con fecha 9 del actual [septiembre de 1867], referente a la reclamación que varios empresarios de teatros de esta Corte hacen para que se prohíban las representaciones lírico-dramáticas en los llamados cafés-cantantes; la Reina (q. D. g.) se ha servido disponer lo siguiente: 1. ${ }^{\circ}$ Quedan suprimidas desde esta fecha las representaciones en los llamados cafés-cantantes de toda obra o producción lírico-dramática. 2. ${ }^{\circ}$ En dichos establecimientos no se podrán ejecutar más que piezas sueltas de música, acompañadas al piano, ya por uno o más cantantes. $3 .^{\circ}$ Los dueños de los cafés que quieran

\footnotetext{
92 La casa de campo: juguete cómico en 1 acto, en prosa y verso, arreglado libremente de la traducción italiana por José Sánchez Albarrán (la primera edición, de la imprenta de José Rodríguez, está fechada en 1865).

${ }^{93}$ Es una malva: juguete cómico en 1 acto arreglado a la escena española por Luis Cortés y Suaña (el manuscrito conservado en la Biblioteca Nacional de España está fechado en 1858).

${ }^{94}$ Una vieja: zarzuela en 1 acto arreglada a la escena española por Francisco Camprodón, música de Joaquín Gaztambide (Teatro de la Zarzuela, 1860).

${ }_{95}$ La cruz del matrimonio: comedia original en 3 actos y en verso de Luis de Eguilaz (Teatro de Variedades, 1861). 1856).

${ }^{96}$ iSálvese el que pueda!!: pieza cómica en 1 acto de Enrique Pérez Escrich (Teatro del Instituto,
} 
ejecutar zarzuelas o comedias en sus establecimientos se sujetarán a pagar la contribución que se impone a los teatros de clase más inferior ${ }^{97}$.

Esta prohibición, desde luego, no tuvo consecuencias inmediatas y a comienzos de 1868 el Recreo y Capellanes seguirían anunciando funciones diarias de juguetes, comedias e incluso algún estreno absoluto. Durante los últimos meses de reinado de Isabel II se continuaron inaugurando nuevos cafés-teatros, con la consecuente preocupación de los empresarios teatrales que observaban cómo perdían al "gran público": "Es en efecto triste que, sin los gastos que constituyen el presupuesto de las empresas, los cafésteatros arrebaten a los teatros formales los espectadores de las galerías y anfiteatros"98. Esta era la clave de la cuestión y no por casualidad-como explicase Nombela- los primeros cafés-teatros madrileños se habían abierto en barrios alejados del centro donde habitaba la mayor parte del público potencial que concurría a estos espectáculos populares de proximidad, como el Recreo, en la calle de la Flor, el de Occidente, cerca de las Vistillas o el de Maravillas, en la calle de San Vicente Ferrer.

A partir de 1868 la situación se invertiría cuando algunos de los teatros llamados "formales", como la Infantil o Variedades, decidiesen asumir paulatinamente el modelo de explotación por horas a la búsqueda de ese mismo público de los cafés-teatros. Se trataba de "renovarse o morir", así que en los años inmediatamente posteriores a la Revolución en Madrid se abrirían nuevos teatros que, desde su inauguración, funcionarían según dicho modelo de explotación, como el Martín y el Calderón ${ }^{99}$ en 1870, el Eslava en 1871 o el Romea en 1873 ${ }^{100}$. Para entonces, tal era la asimilación de la idea del teatro por horas con el espacio de los cafés, que al inaugurarse el Martín se dijo de él que se dedicaba "a caféteatro"101.

Ateniéndonos a los números, el temor de los empresarios teatrales estaba bien fundado. El formato "de a real la pieza" (barato, breve, divertido e informal) resultaba indudablemente más competitivo frente al modelo tradicional de la función teatral única (larga, cara, ecléctica y protocolaria) dentro de las estructuras de ocio del Madrid tardoisabelino, máxime si

\footnotetext{
${ }_{97}$ Madrid, 17 de noviembre de 1867, Ministerio de la Gobernación (Subsecretaría. Sección de Orden Público), negociado segundo.

98 Julio Nombela: "Misterios de Madrid”, La Época, 14-9-1867, p. [1]

${ }_{99}$ Nos referimos al Teatro Calderón de la calle de la Madera, en el que se estrenó el célebre Macarronini I de Eduardo Navarro Gonzalvo el 30 de noviembre de 1870. En algunas fuentes consta como teatro-café.

100 Más teatros fundados durante aquellos años y que funcionaban por horas desde su fundación eran el Bretón de la calle Fuencarral, el de Luzón en la calle homónima o el del Prado en el Salón del Prado. El de la Alhambra en la calle de la Libertad no tardó tampoco en dedicarse al teatro por horas.

${ }^{101}$ Asmodeo [Ramón de Navarrete]: "Revista de teatros", La Época, 18-12-1870, p. [4].
} 
tenemos en cuenta que el jornal medio en 1867 era de 7 reales ${ }^{102}$. Regresando al Anuario administrativo y estadístico de la provincia de Madrid para el año 1868 , es posible hacer una estimación del aforo total de los teatros madrileños suponiendo que algún día ofreciesen todos ellos una función a teatro lleno simultáneamente: 10.500 espectadores. Si hacemos lo propio con los cafés-teatros y multiplicamos el aforo total por cuatro (suponiendo que se renovase la totalidad del público en cada función) el resultado es más que llamativo: 11.900 espectadores.

Por tanto, en lo que atañe a las últimas tres temporadas teatrales del reinado de Isabel II asistimos en Madrid a una auténtica eclosión o bum teatral, no pudiendo estar más de acuerdo con Serge Salaün cuando afirma que, durante sus primeros meses de vida, "el género chico tuvo ribetes de revolución social y cultural" ${ }^{103}$. De esta manera podemos comprender, por ejemplo, el reiterado contenido político -no precisamente en tono paródico- del primer repertorio escrito ex profeso para estos teatros por autores como Calixto Navarro una vez promulgada la citada libertad de teatros a comienzos de $1869^{104}$. En los primeros teatros por horas de Madrid, junto a juguetes, comedias y algún melodrama de gusto popular, se representaban obras serias, frecuentemente alegóricas, sobre la revolución y los valores democráticos que esta encarnaba; en definitiva, un teatro tan patriótico o político como barato y sencillo para el público que había protagonizado la Gloriosa. En este sentido podríamos plantear una relectura del Sexenio Democrático en tanto que culminación de un proceso en la historia de los espectáculos: el teatro por horas no fue una consecuencia de la Revolución de 1868, pero la Septembrina fue posible por la existencia de facto de esa sociedad protodemocrática que disfrutaba del teatro por horas más de dos años antes del “¡Viva España con honra!”. Esta nueva manera de producción reflejaba, por tanto, una división entre la media-alta burguesía y la media-baja burguesía, que para entonces ocupaban distintos lugares del espacio público (teatros frente a cafés-teatro) y sin cuya ruptura definitiva no sería posible entender hoy la Gloriosa.

Que el teatro por horas había supuesto una auténtica revolución promovida desde el café al teatro (de abajo hacia arriba, por poca categoría que tuviesen el Recreo o la Infantil) ya fue apreciado por Ángel Fernández de los Ríos en su célebre Guía de Madrid de 1876 al comentar sobre los teatros de la recién reestablecida Corte:

102 Pedro Villa Mínguez: "Precios alimentarios y nivel de vida en Madrid (1851-1890)", Madrid en la sociedad del siglo XIX, Luis Enrique Otero Carvajal y Ángel Bahamonde (eds.), vol. 2, Madrid, Comunidad de Madrid, Consejería de Cultura, 1986, p. 287.

103 S. Salaün: "El público de los espectáculos (mal llamados) menores...", p. 179

${ }^{104}$ Gregorio de la Fuente Monge: "El teatro republicano de la Gloriosa", Ayer, n. ${ }^{\circ}$ 72, 2008 [dossier "Espectáculo y sociedad en la España contemporánea"], pp. 83-119. 
Se ha operado en Madrid una verdadera revolución teatral que es, a no dudarlo, un progreso, pero que pudiera y debería serlo mucho mayor: rápidamente se han ido creando teatros de segundo orden que por el aliciente de la baratura, un real cada pieza, han despertado la afición al teatro en las clases sociales poco favorecidas de la fortuna, les han arrancado de la taberna y llevado a alternar con las demás clases, desde la aristocracia que a esos teatros concurre la noche de moda, hasta la media, que siendo pobre no deja de ser vana y gastadora ${ }^{105}$.

El testimonio de Fernández de los Ríos resulta en su moralismo paternalista paradigmático de la apropiación (Serge Salaün habla de recuperación ${ }^{106}$ ) del teatro por horas y su repertorio durante los primerísimos años de la Restauración por parte de la oligarquía económica y social que aspiraba a garantizar el restablecimiento del orden social burgués después de la experiencia republicana. Todo elemento potencialmente subversivo del primer género chico iría desapareciendo de manera que a finales de siglo podríamos hablar, de acuerdo con Salaün, de un teatro "de derechas" 107 representativo de la cultura identitaria de las burguesías españolas, desde la más baja (que renunciaría de su actitud revolucionaria de 1868) a la más alta y filoaristocrática que concurriría a teatros como el Apolo, al salir del Real, con su célebre cuarta función. A partir de 1900, con la apoteosis de la zarzuela sicalíptica y la aparición de una voz alternativa como fue la del libretista Antonio MartínezViérgol (Ruido de campanas, Las bribonas, El poeta de la vida, etc.) sí existió un género chico indudablemente "incómodo" para neocatólicos y conservadores, aunque en pocos años quedó diluido ante el auge de la sofisticada opereta vienesa de la Edad de Plata ${ }^{108}$.

En conclusión, si como hemos visto el teatro por horas tiene raíces auténticamente isabelinas, no podemos afirmar lo mismo de su repertorio de nueva creación, el género chico. Solo durante el Sexenio podemos confirmar la escritura de manera masiva de nuevas obras (también líricas) para teatros como el Salón Eslava, el Martín o los Jardines del Buen Retiro. Estos son los teatros que hacia 1871 son denominados en prensa como "de a real la pieza" y en los que inician sus carreras como compositores de zarzuela autores de una nueva generación como Chueca, Nieto, Rubio o Bretón. Una mirada al catálogo de estos autores echa por tierra, desde luego, la teoría de La canción de la Lola de 1880 como zarzuela pionera del género chico y pone en cuestión el modelo construido por Deleito y Piñuela. El

\footnotetext{
105 Ángel Fernández de los Ríos: Guía de Madrid. Manual del madrileño y del forastero, Madrid, Oficinas de "La Ilustración Española y Americana", 1876, p. 573.

106 S. Salaün: "El público de los espectáculos (mal llamados) menores...", p. 179.

107 S. Salaün: "Política y moral en el teatro comercial a principios de siglo", Les espectacles en Espagne (1875-1936), París, Presse Sorbonne Nouvelle, 2011, pp. 65-85.

108 Christopher Webber: "The alcalde, the negro and "la bribona": "género ínfimo" zarzuela, 19001910", De la zarzuela al cine..., pp. 63-76.
} 
concepto de "teatro por horas" aparecería a partir de la década de los ochenta del siglo XIX ${ }^{109}$ y el de "género chico" (con música o sin ella) tan solo a finales de dicha década y de manera ya normalizada durante los noventa. Hay que tener en cuenta, en cualquier caso, que por "género grande" no se entendía exclusivamente la zarzuela de más de un acto, sino también la alta comedia y el drama. De mediados de los noventa en adelante, con su consagración en el Teatro Apolo y la Zarzuela, por "género chico" empezaría a designar, casi exclusivamente, las zarzuelas en un acto.

En la actualidad quizás debiéramos someter a crítica el concepto de género chico. Desde el más puro formalismo podríamos aseverar que la duración no hace al género por lo mismo que el cortometraje discutiblemente podría ser considerado en tanto que género cinematográfico. Sin embargo hoy, cuando se discute hasta qué punto la necesaria sumisión al formato corto de las narrativas y estéticas audiovisuales implicaría la definición de un género en sí mismo ${ }^{110}$ nos preguntamos si algo parecido pudo suceder con el género chico durante el último tercio del siglo XIX. De hecho, ya hemos citado cómo, desde el punto de vista de los estudios culturales, sí parece existir cierto consenso en afirmar la existencia de un género chico como género o manifestación cultural y teatral que puede definirse no tanto por las características de los productos (ese repertorio casi infinito de obras) como por los "usos" de los mismos. En este sentido, remitiéndose a la teoría de los polisistemas de Itamar Even-Zohar, Álvaro Ceballos ha afirmado recientemente que "el género chico es una práctica escénica con elevada cohesión social y sociosemiótica, en la que las decisiones individuales se diluyen y limitan"111.

Poniendo el acento sobre sus partituras, el género chico fue un formato de producción que permitió la creación de obras tan dispares como Château-Margaux, El año pasado por agua, Gigantes y cabezudos, El húsar de la guardia o las "traducciones chicas" de Barba Azul, Boccaccio, La viuda alegre o El maestro Campanone. Sainetes, juguetes, óperas bufas, revistas... subgéneros de una historia más general y cosmopolita: la de la opereta y la ópera cómica española o, en otras palabras, la del teatro musical popular español ${ }^{112}$. Hemos

109 Todavía hoy resulta de obligada lectura el análisis que ofrece sobre la cuestión un testigo de excepción como José Yxart: El arte escénico en España, vol. 2, Barcelona, Imp. de "La Vanguardia", 1896, p. 77 y ss.

${ }^{110}$ Ignacio Lasierra Pinto y Joseba Bonaut Iriarte: "Estrategias narrativas y estéticas en el paso del cortometraje al largometraje: análisis del caso de Paula Ortiz", Miguel Hernández Communication Journal, n. ${ }^{\circ} 7,2016$, p. 419.

${ }^{111}$ Á. Ceballos Viro: "El cine en el género chico (1897-1936)", Hecho Teatral, 17, 2017, p. 39.

112 La discutible aplicación de etiquetas genéricas convencionales para este repertorio está animando en la actualidad a investigadores del ámbito de la opereta a utilizar el concepto más cómodo e inclusivo de popular musical theatre. Junto al citado estudio de referencia de Clinton D. Young hay que citar la reciente monografía de Len Platt, Tobias Becker y David Linton (eds.): Popular Musical Theatre in London and Berlin, 1890-1939, Cambridge-Nueva York, Cambridge University Press, 2014. 
de insistir, por último, en la necesidad de reestudiar autores y obras profundizando en el análisis para poder ir más allá de las etiquetas -nunca inocentes- que sus creadores o la crítica utilizaron. Solo así podremos deconstruir el propio concepto de zarzuela, reubicando tan vasto e interesante repertorio en los discursos historiográficos actuales sobre el teatro musical occidental de los siglos XIX y XX.

Recibido: 25-4-2017

Aceptado: 9-8-2017 